\title{
Congenital Hepatic Fibrosis in Jamaican Children
}

\author{
MARIGOLD J. THORBURN, COLIN G. MILLER, and GERRIT BRAS \\ From the Departments of Pathology and Paediatrics, University of the West Indies, Kingston, Jamaica
}

In 1961, Kerr, Harrison, Sherlock, and Walker described a series of children, all but one under 10 years of age, whose main features were hepatosplenomegaly or bleeding oesophageal varices. They reviewed the published material fully, and differentiated their cases from 'juvenile cirrhosis' following neonatal hepatitis, blood group incompatibility, Wilson's disease, and fibrocystic disease of the pancreas. They credited MacMahon (1929) with being the first to have recognized a fibrotic change in the liver, distinct from cirrhosis and not usually associated with disease of the pancreas. The condition accounted for a significant proportion of portal hypertension seen in children and young adults. The clinical course was more benign than that of cirrhosis, there was no jaundice, and liver function tests were normal. They proposed the name 'congenital hepatic fibrosis', subscribing to the views of MacMahon (1955) and Parker (1956), that the condition was congenital and that the fundamental anomaly was an excess of fibrous tissue associated with an abnormality of portal veins. Other authors who have been mainly concerned with the condition in adults (Moschcowitz, 1906; Norris and Tyson, 1947; Comfort, Gray, Dahlin, and Whitesell, 1952; Melnick, 1955) had emphasized the presence of cystic elements, and the association with polycystic kidneys and other congenital abnormalities.

Since 1961, we have diagnosed this condition either clinically or at necropsy, in 8 young children. Since they presented features not much emphasized previously and we have been able to perform chromosome studies in 3, we here present the clinicopathological data on these cases.

\section{Material and Methods}

All 8 patients were children attending the University College Hospital of the West Indies. 3 were diagnosed at necropsy, and 2, who were sisters, were diagnosed in retrospect. 3 patients, seen since 1964, have been more fully investigated. Cytogenetic studies were performed

Received September 22, 1966. in 3. All children were of predominantly negro extraction. The diagnosis was confirmed either by needle biopsy or at necropsy. Pathologically we defined 'congenital hepatic fibrosis' as a disease process affecting the whole liver, in which the architecture was preserved. The portal tracts showed increase in fibrous tissue and increased numbers of bile-ducts, some of which might be dilated but showed no sign of obstruction. The cellular infiltrate varied in type of cells and in amount. The lesion was essentially localized to the triads, though the process might extend into the liver lobule to connect portal triads. There was no marked liver cell damage. The concomitant lesion in the kidney was that described as 'medullary sponge kidney'; the kidneys were enlarged and the medulla was cystic. Microscopically, this was due to dilatation of distal and collecting tubules. There was no loss of glomeruli and, primarily, no increase in fibrous tissue in the cortex. This picture is very similar to that of Type 1 polycystic kidney of Osathanondh and Potter (1964), though they state that this type is not compatible with life for long after birth.

\section{Results}

Clinical features. These varied widely in the different cases and, in fact, the diagnosis was not even suspected clinically in the first 3 cases. The main features are summarized in Table I. The age at presentation was under 2 years in all of the patients. Case 6 was a more typical example of congenital hepatic fibrosis, as described by Kerr et al. (1961), and an account of her clinical course and pathological findings follows.

Case 6. J. McD., a girl, was born in October 1963 weighing $3628 \mathrm{~g}$. $(8 \mathrm{lb}$.) following a normal delivery. Her mother had been given a course of penicillin during the antenatal period for a positive VDRL. She was breast-fed for two months and weaned on to a diet inadequate in calories and protein. There is no known consanguinity and no family history of liver or kidney disease. There are 3 sibs, 1 half-sib who is normal, and 2 full sibs, 1 of whom has the disease (Case 7). She was first admitted in April 1964 at the age of $6 \frac{1}{2}$ months with the history of recurrent respiratory infections since the age of 2 weeks, abdominal swelling for 2 months, and vomiting and oedema of the legs for 8 days. On examination, she was pale, with tachypnoea and gross 


\begin{tabular}{ccc}
$\begin{array}{c}\text { Case } \\
\text { No. }\end{array}$ & $\begin{array}{c}\text { Age at } \\
\text { Presentation }\end{array}$ & $\begin{array}{c}\text { Age Last } \\
\text { Seen }\end{array}$ \\
\cline { 2 - 3 } 1 & $5 \mathrm{mth}$. & $9 \mathrm{mth}$. \\
2 & $7 \mathrm{wk}$. & $8 \mathrm{mth}$. \\
3 & $2 \mathrm{yr}$. & $2 \mathrm{yr}$. \\
4 & $16 \mathrm{mth}$. & $6 \mathrm{yr}$. \\
5 & $10 \mathrm{mth}$. & $12 \mathrm{yr}$. \\
6 & $6 \mathrm{mth}$. & $17 \mathrm{mth}$. \\
7 & $5 \mathrm{mth}$. & $6 \mathrm{mth}$. \\
8 & $16 \mathrm{mth}$. & $11 \mathrm{yr}$.
\end{tabular}

\begin{tabular}{l} 
Mode of Presentation \\
\hline Fever; lt. loin mass; hepatomegaly \\
Lt. loin mass-kidney \\
Anaemia; respir. infect. \\
Weight loss; hepatosplenomegaly \\
Hepatosplenomegaly \\
Respir. infect.; abdom. swelling; anaemia \\
Gastro-enteritis \\
Gastro-enteritis; fever and swelling
\end{tabular}

\begin{tabular}{cc} 
Fever & $\begin{array}{c}\text { Abdom } \\
\text { Pain }\end{array}$ \\
\hline++ & - \\
++ & - \\
+ & - \\
+++ & - \\
+++ & - \\
++ & +++
\end{tabular}

oedema of the lower half of her body (Fig. 1). There was no fever, jaundice, or lymphadenopathy. The heart was slightly enlarged. A soft systolic murmur was heard all over the praecordium and a few basal crepitations were heard in the chest. The liver was hard and tender, and the spleen was firm. Both organs extended to the umbilicus and there was a large umbilical hernia. The left kidney was palpable.

Investigations showed a severe iron-deficiency anaemia, - $\mathrm{Hb} 4.5 \mathrm{~g} . / 100 \mathrm{ml}$., MCHC $25^{\circ}{ }_{0}$, and a leucocytosis (see Table II). Liver function tests showed gross hypoalbuminaemia, hyperglobulinaemia, and a raised thymol turbidity (Table III). Chest $x$-ray film showed cardiomegaly. An electrocardiogram suggested non-specific myocardial damage with right bundle-branch block.

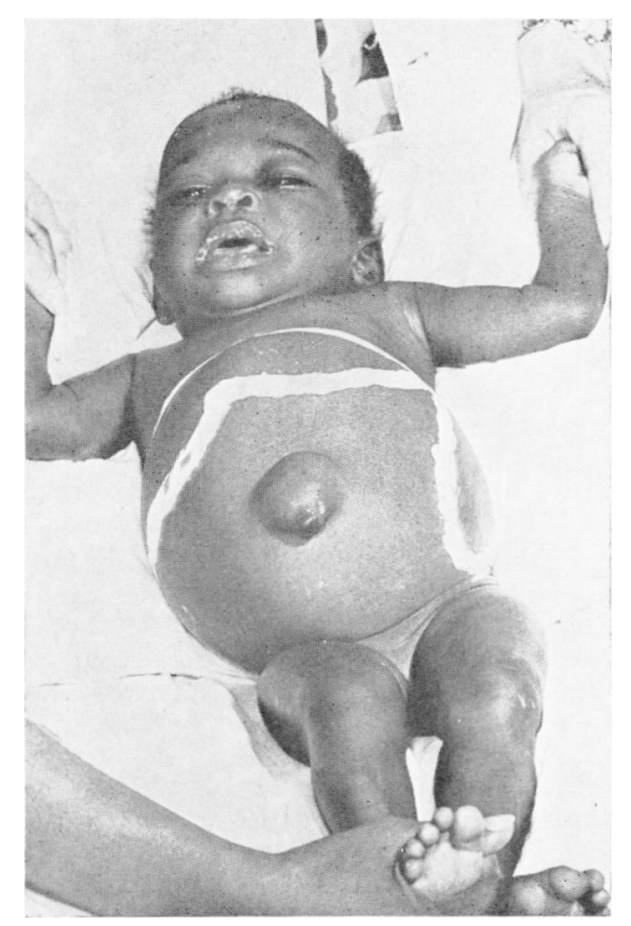

FIG. 1.-Case 6 at 7 months.
The haemoglobin rose slowly on oral iron and folic acid to $7 \mathrm{~g} . / 100 \mathrm{ml}$., but in spite of antibiotics she continued to have intermittent attacks of fever lasting 4 to 6 days for which no cause could be found. During this time, her blood urea rose to $70 \mathrm{mg} . / 100 \mathrm{ml}$. and the liver function tests deteriorated. An intravenous pyelogram showed a large right kidney. A liver biopsy in June 1964 showed the features of congenital hepatic fibrosis.

She was discharged after 3 months but was readmitted 5 days later with fever, diarrhoea, and vomiting. Abdominal distension had increased, and the haemoglobin had fallen to $4 \mathrm{~g}$. $100 \mathrm{ml}$. The blood urea was 43 mg./100 ml., but other investigations were relatively unchanged. She responded to antibiotics, but for the next 9 months she continued to have intermittent fever. The erythrocyte sedimentation rate was $143 \mathrm{~mm}$./hr. and Klebsiella aerogenes was cultured from a liver biopsy in September 1964. In October, she developed lobar pneumonia and, in February 1965, she developed bronchopneumonia which responded slowly to antibiotics. She was readmitted for the last time in March with a recurrence of symptoms which failed to respond to therapy. She died in March 1965 aged 17 months.

Necropsy showed an emaciated child, weighing only $7 \cdot 3 \mathrm{~kg}$. There was no icterus or oedema. The heart was much enlarged, weighing $74 \mathrm{~g}$. (normal $46 \mathrm{~g}$.), the enlargement affecting mainly the right ventricle. The lungs were congested. In view of the reported emphysema in a case of congenital hepatic fibrosis (Williams, Scheuer, and Heard, 1964) and of the right ventricular hypertrophy, one lung was inflated with formalin and sections were taken of the whole lung after embedding in gelatin. There was no evidence of primary lung disease. The liver was more than twice the normal size (weight $770 \mathrm{~g}$.) and there were adhesions to the diaphragm and spleen. The capsule was thick and fibrotic. The parenchyma on cross-section was hard, yellowish, and fibrotic, but the normal architecture was preserved. The gall-bladder was enlarged and contained pale bile, but there was no evidence of obstruction in the biliary tree.

The spleen was four times the normal size, weighing $107 \mathrm{~g}$. and was fibrotic, with adhesions to the diaphragm. The pancreas was not remarkable. The kidneys weighed a total of $362 \mathrm{~g}$. (normal $80 \mathrm{~g}$.). There were cysts protruding from the surface, and on cross-section, 


\begin{tabular}{|c|c|c|c|c|c|c|c|c|}
\hline $\begin{array}{l}\text { Gastro- } \\
\text { intestinal } \\
\text { Bleeding }\end{array}$ & $\begin{array}{l}\text { Hepato- } \\
\text { megaly }\end{array}$ & $\begin{array}{l}\text { Spleno- } \\
\text { megaly }\end{array}$ & Ascites & $\begin{array}{c}\text { Polycystic } \\
\text { Kidneys }\end{array}$ & Anaemia & $\begin{array}{l}\text { Congest. } \\
\text { Cardiac } \\
\text { Failure }\end{array}$ & Uraemia & Outcome \\
\hline- & +++ & ++ & - & + & ++ & - & - & Died of anaemia \\
\hline- & ++ & - & - & + & + & - & - & Strangulated hernia; died \\
\hline- & +++ & ++ & + & - & +++ & +- & - & Died; sickle-cell anaemia \\
\hline- & +++ & -+ & + & - & - & - & - & Died at home \\
\hline- & $+t+$ & -+ & - & - & - & - & - & Alive and well \\
\hline- & ++ & ++ & - & - & + & - & $:-$ & Alive \\
\hline- & $++t$ & + & - & + & ++ & - & - & Alive and well \\
\hline
\end{tabular}

they were seen to be distributed throughout the medulla in a rather irregular manner. The remaining remarkable feature was the massive, fleshy enlargement of all the lymph nodes in the abdomen. There were welldeveloped oesophageal varices.

On histological examination, the left ventricle showed areas of fibrosis and there was some arterial thickening. The lungs showed extensive oedema and focal bronchopneumonia. The liver showed broad bands of fibrosis extending between portal triads, and in many areas breaking up the pattern. These contained many large bile-ducts and there was some bile-duct proliferation. There was also a heavy infiltration with polymorphs, lymphocytes, and plasma cells. There was only minimal necrosis of liver cells and there was no evidence of bile stasis. The spleen was congested and showed extramedullary haemopoiesis. There was some increase in fibrosis in the pancreas but no evidence of cystic disease. The lymph nodes showed hyperplasia and extramedullary haemopoiesis.

In the kidneys, the medulla was most severely affected. The collecting tubules showed gross dilatation which extended up into the distal convoluted tubules. The glomeruli were relatively unaffected though occasional sclerosis was seen. There were also foci of chronic inflammatory cells, and in the medulla, there was considerable fibrosis around cysts and the dilated $\stackrel{\omega}{\sigma}$ tubules. There was evidence of arteriosclerosis. The appearances were more characteristic of type 3 polycystic? kidneys of Osathanondh and Potter (1964), though there $\vec{N}$ appeared to be no loss of nephrons. The arterial i hypertrophy and myocardial fibrosis suggested that there $₫$ was some systemic hypertension, probably secondary to ${ }_{y}$ renal disease. The right ventricular hypertrophy, $\bullet$ however, remained unexplained, as there was no $\frac{}{3}$ evidence of primary lung disease to account for it.

Intermittent fever was the commonest and most prominent symptom in our cases. Sickle-cell $\stackrel{5}{\oplus}$ anaemia could have accounted for this symptom in $\overrightarrow{\vec{\theta}}$ one child, and in the other 5 affected patients, uppeg respiratory tract infections, gastro-enteritis, pnev monia, and septicaemia were associated with sone of the febrile episodes. Klebsiella aerogenes was cultured from the liver biopsies in Cases 6 and 8 and was also grown from the blood-stream in Case 8 . Kerr et al. (1961) reported one case with persistent pyaemia due to Friedlander's bacillus, one of the klebsiella group, and it appears that these children may be especially susceptible to infections by this group of organisms. In spite of the high incidence

TABLE II

Laboratory Investigations

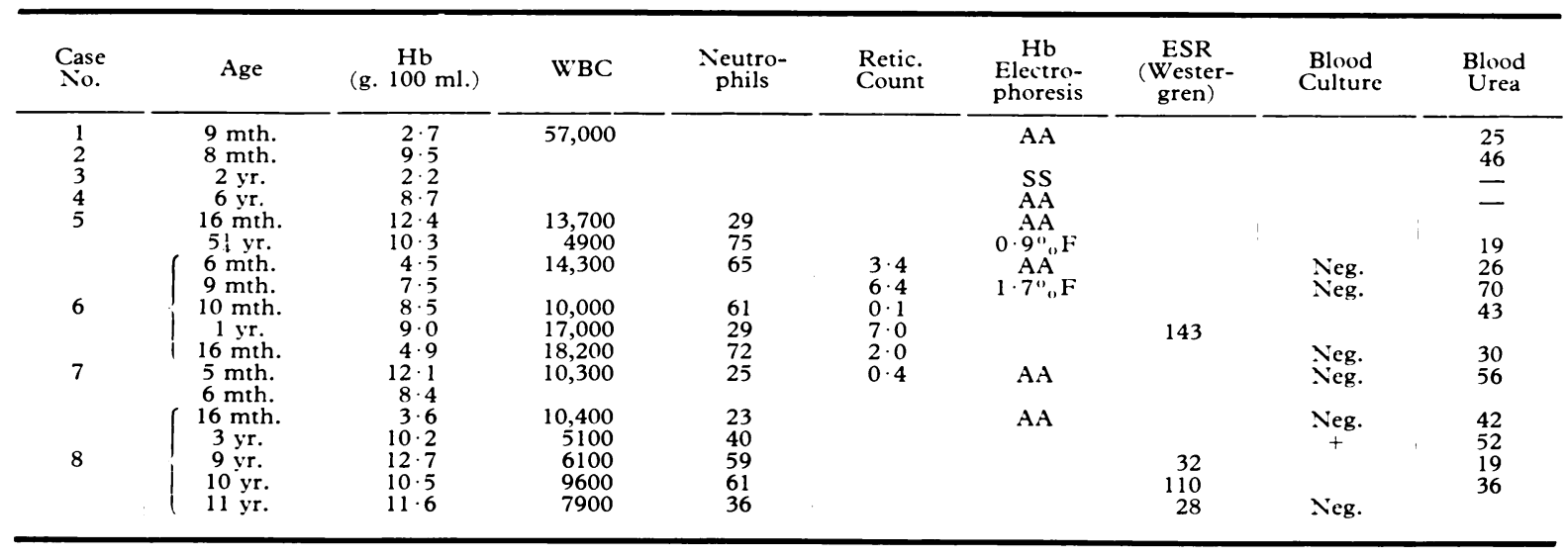




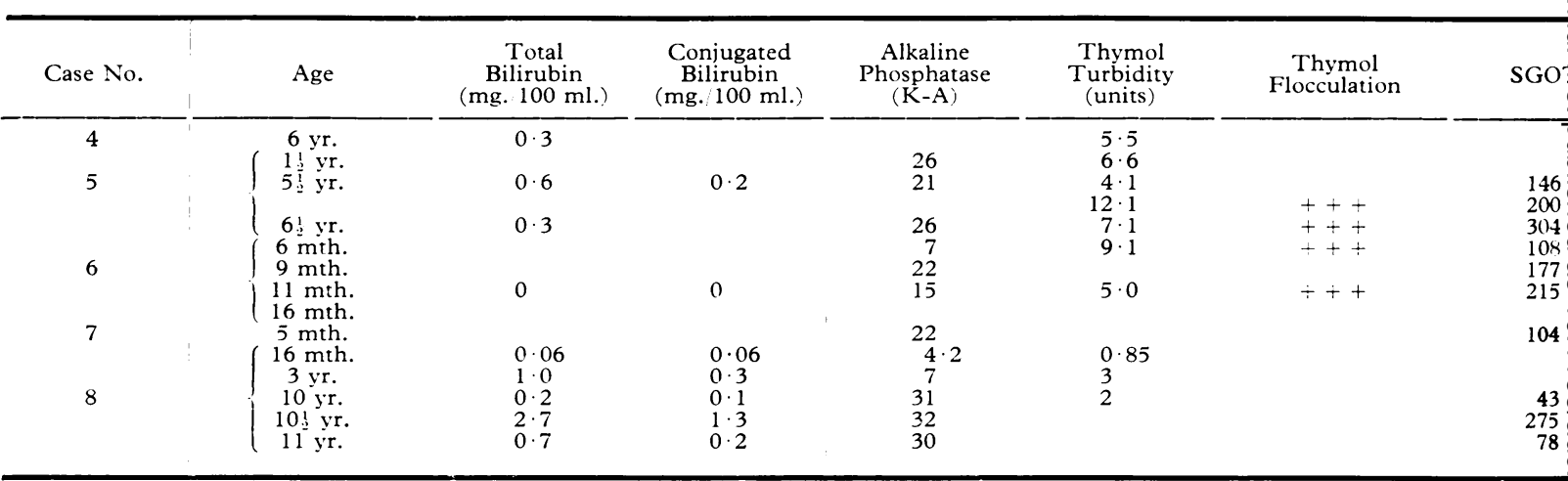

of infection in our patients, no cause could be found for many of their febrile episodes, and on several occasions, the fever subsided without the use of antibiotics. Abdominal pain was experienced $b_{:}$ only one of our patients who was old enough to complain. Sometimes this was associated with attacks of fever, but not invariably.

Anaemia was a feature in 6 of our patients, and in 4 the haemoglobin was less than $7 \mathrm{~g} . / 100 \mathrm{ml}$.; 1 of these 4 patients was suffering from homozygous sickle-cell anaemia from which he died soon after admission and another died before the cause of anaemia could be investigated. Of the other 2 , Case 6 had severe iron-deficiency anaemia at 6 months of age, which was associated with malnutrition and recurrent respiratory infections; no source of blood loss was detected and the anaemia responded only very slowly to haematinics. Case 8 presented with a mixed hypochromic macrocytic anaemia at 16 months, which failed to respond to oral iron, but, following transfusion responded well to folic acid. 3 patients, including the one with sickle-cell anaemia, showed severe cardiomegaly, accompanied by macroscopic and microscopic myocardial fibrosis. This may be related to the anaemia, as our living children who have no severe degree of anaemia have, at present, no evidence of cardiomegaly.

As in the patients described by Kerr et al. (1961), the liver was clinically smooth, much enlarged, and of very firm consistency in the majority of cases. This finding, in the presence of splenomegaly and other signs of portal hypertension, may be of diagnostic value, as it contrasts with the small, irregular liver often seen in cirrhosis.

Ascites was noted at some time in 3 of our patients, 2 of whom had other signs of congestive cardiac failure. Hepatic failure with ascites and coma has been rare in the experience of other workers, though it can complicate congenital hepatic fibrosis, especially after haemorrhage. Most of the reported cases had good liver function, both clinically and biochemically, the only common abnormality being a raised serum alkaline phosphatase, though hyperbilirubinaemia was only temporarily present. There was evidence of active hepatocellular damage in 4 of the 5 patients in whom liver function tests were performed (Table III). Malnutrition in association with recurrent infection might possibly explain this.

The possible differential diagnoses in Jamaica of hepatomegaly due to malnutrition or veno-occlusive disease were usually easily excluded on clinical grounds. In only one (Case 4), was veno-occlusive disease considered a possibility and this was excluded by histological examination.

Polycystic kidneys were demonstrated in 4 of our patients. Although 3 of them had raised blood urea levels on one or more occasions, none of them have died of uraemia.

One of the children (Case 8) is unable to concentrate her urine above a specific gravity of 1010 . Her blood pressure is normal and as she is now aged 11 years, it seems unlikely that she will develop severe renal failure in the near future, in view of the recognized natural history of the disease (Dalgaard, 1957). The high mortality rate in our series may be explained by the fact that the majority of our cases have been recognized in retrospect. The cause of death in the 4 patients who came to necropsy could be attributed directly to congenital hepatic fibrosis in only 2 .

Investigations. Positive laboratory findings are summarized in Tables II and III. As liver disease was not diagnosed in the first 3 children, liver function tests were not performed in these. 


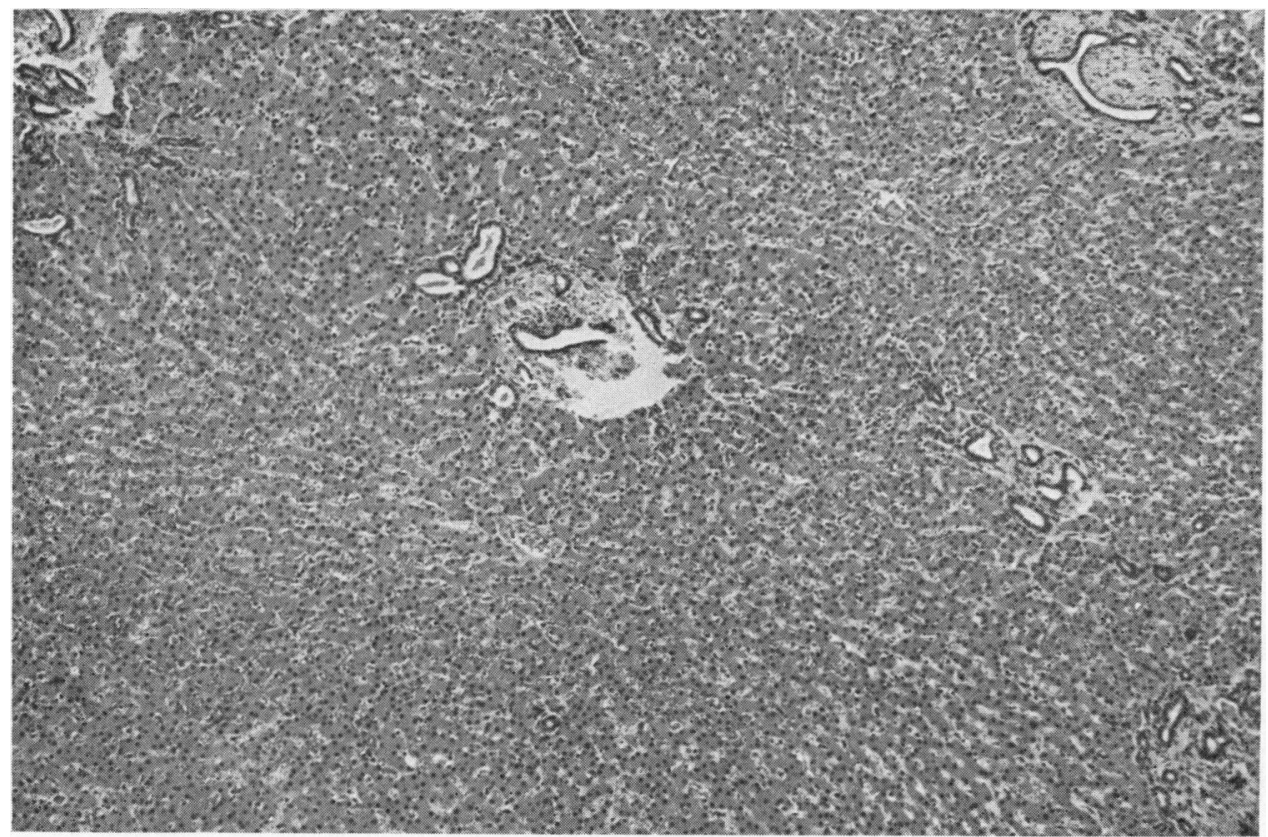

FIG. 2.-Case 2. Low-power view of liver, showing prominent portal triads. $(H$. and $E . \quad \times 66$.

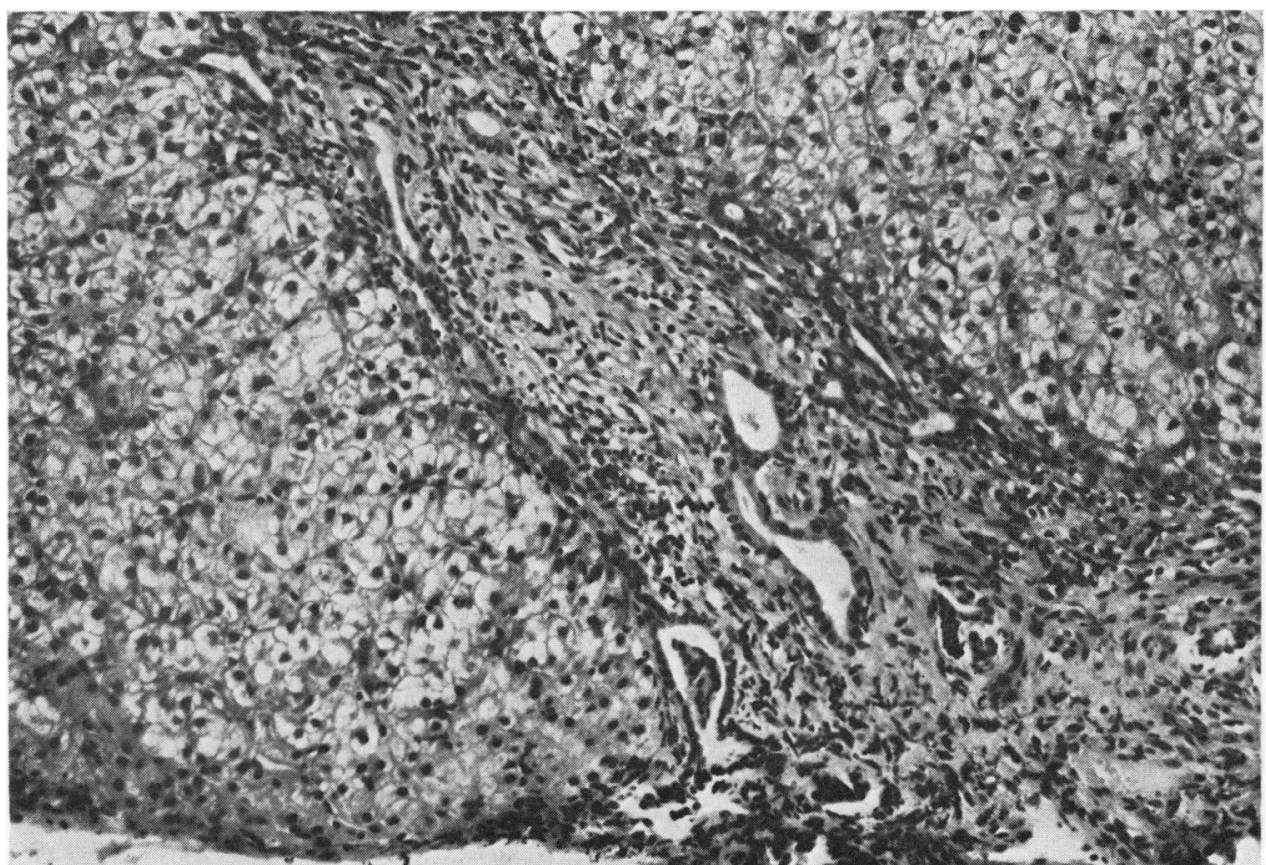

Fig. 3.-Liver biopsy of Case 6, showing increase in bile-ducts and connective tissue. (H. and E. $\times 170$. 
Histological features.

(a) LIVER. The disease was diffusely present throughout the liver. The appearances were quite characteristic; they might in fact have suggested the diagnosis after seeing the first low-power field. The portal triads stood out because of the increase in bile-ducts and in connective tissue (Fig. 2 and 3).

Connective tissue. Some increase was invariably present in the portal triads, and it sometimes extended far into the parenchyma into Rappaport's zone 3-linking portal triads, and leaving the hepatic veins unaffected (Fig. 4).

Bile-ducts. These were usually very numerous, but appeared well formed and a lumen was commonly present (Fig. 5). Although they could be relatively wide (Fig. 2), they appeared unobstructed (Fig. 5). However, they occasionally contained polymorphs as seen in Case 6. Bile-duct destruction was limited. Small bile-ducts were seen in the parenchyma adjacent to portal triads: these had very little fibrous tissue accompanying them (Fig. 5). Some of these were seen to link up with the liver cells, suggesting transformation of cell plates into bile-ducts.
Vessels. Arteries were usually easily recognized, but the portal veins were frequently difficult to distinguish with any degree of confidence. Capillaries were profuse in the portal triads and fibrous bands. Hepatic vein branches were unaffected, and in cases with much fibrosis the terminal hepatic (central) veins and the sublobular veins were situated in the centre of the unaffected 'lobules' of liver tissue (Fig. 4).

Parenchymal cells. There was little evidence of necrosis. Although the junction with triads or fibrous bands was in some areas well demarcated, very frequently a limiting membrane of cell plates was absent, the connective tissue apparently penetrating into the surrounding parenchyma; in the latter process the liver cells were apparently choked to necrosis or transformed into bile-ducts (Fig. 4). Such disruption of the limiting membrane (Elias, 1953) was most obvious in the cases accompanied by inflammation, but it was also seen in the upper part of Fig. 5 when inflammatory infiltrate in the triads was absent. There were no regenerative nodules.

Infiltrate. This varied a great deal. Polymorphs

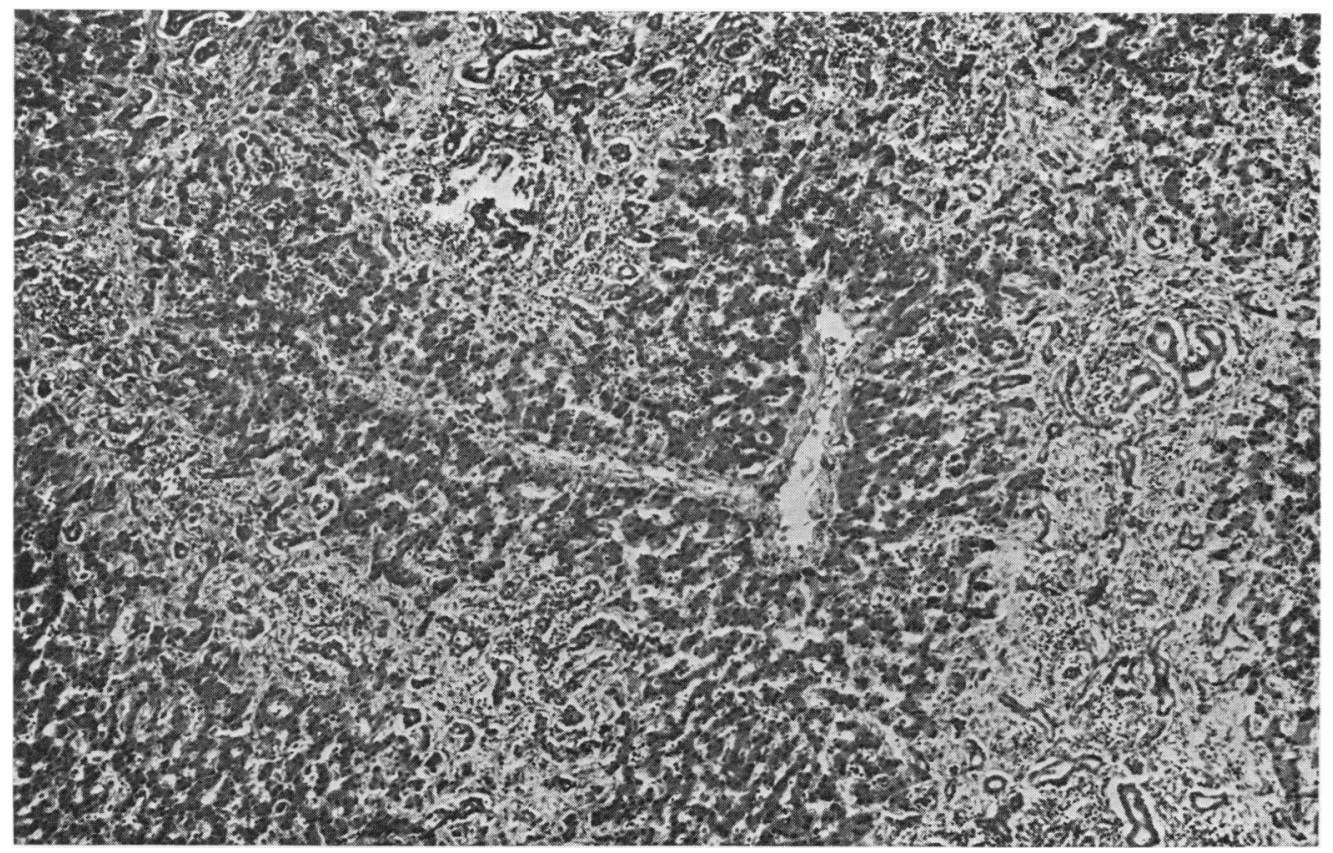

FIG. 4.-Liver in Case 1, showing extension of connective tissue into parenchyma. (H. and E. $\times 164$. 


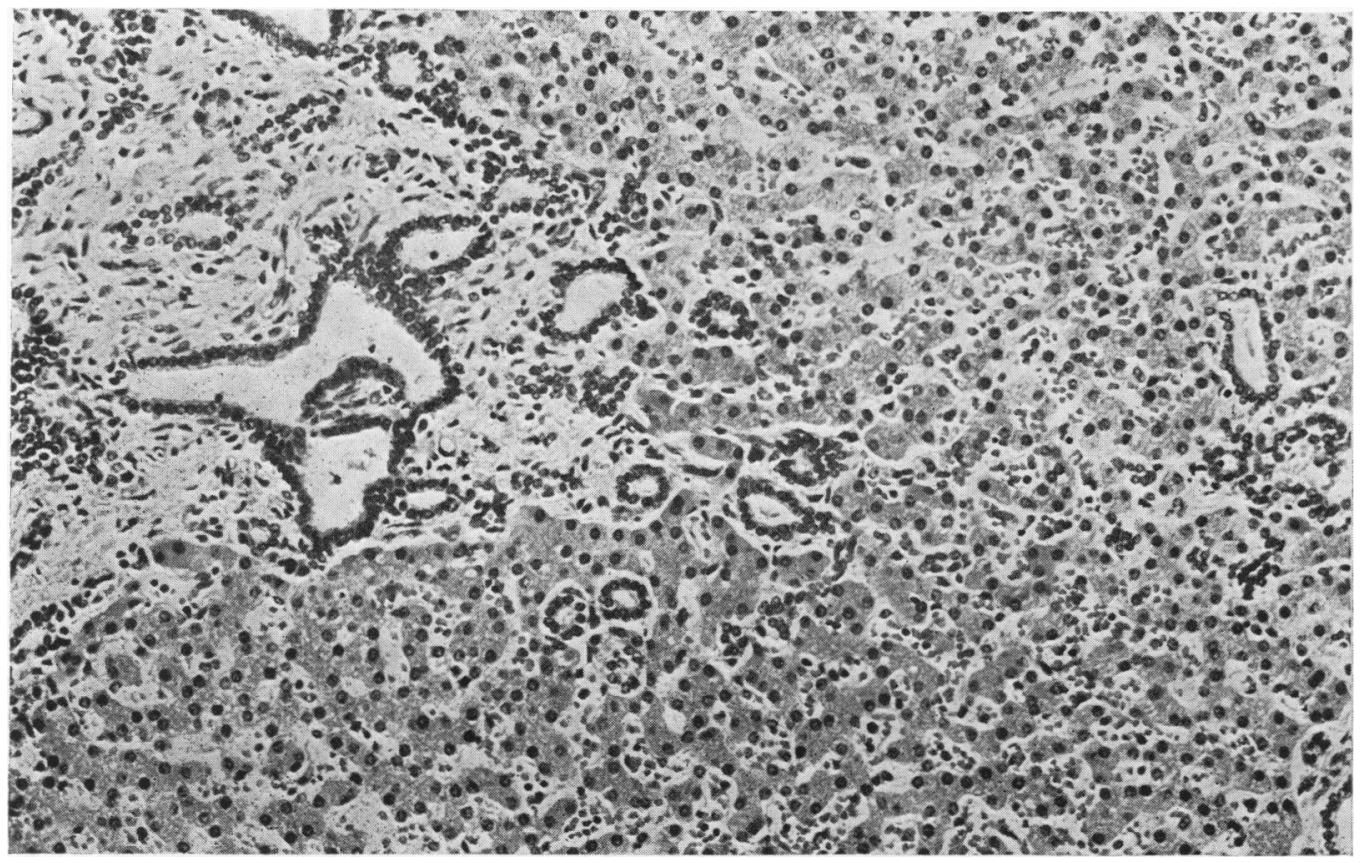

Fig. 5.-Liver of Case 2, showing well-formed bile-ducts with unobstructed lumen. (H. and E. $\times$ 156.)

were commonly seen and were present in significant numbers in several cases, though lymphocytes and plasma cells were less plentiful.

(b) KIDNEYS. In the three cases with polycystic kidneys, the gross and histological features varied, though the variation appeared to be more a difference in degree than a basic difference in type. Case 2 showed features typical of Osathanondh and Potter's (1964) type 1, while Case 1 appeared to be a milder form of the same condition. Case 6 resembled more type 3 , however, with increased fibrosis especially around the tubules and cysts. Also the extent of the disease was variable in Case 6 . In no case did there appear to be any loss of nephrons. Dissection of the nephrons in Case 6 showed features almost identical to those described for type 1 (Osathanondh and Potter, 1964). There was saccular dilatation of the collecting tubules almost up to the proximal tubules, and small cysts were also seen in the proximal convoluted tubules. The tubules did not terminate in cysts without nephrons, and the cysts were directly continuous with the tubular lumen, and were not in any way isolated.

\section{Discussion}

Following the report by Kerr et al. (1961) who reviewed the earlier published papers, Sweetnam and Sykes (1961) described a family of 3, 1 of whom was under 10 years. One patient had liver disease only and the others had both liver and kidney disease. Hickie and Garvan (1962) described a mother and 2 daughters, all presenting with symptoms in middle age: 2 of these patients had hepatic fibrosis and 1 had both liver and kidney disease.

In 1964, Althoff described 3 children, of whom 2 came to necropsy and showed the typical pathological picture of congenital hepatic fibrosis, called by him cholangiodysplastic pseudocirrhosis. There were associated congenital abnormalities in other organs. Both children had a 'slight degree' of $\mathrm{ABO}$-erythroblastosis. We have seen no other reports of this disease.

In the childhood as well as in the adult manifestation of this disease, there is a strong family history. Of our 8 cases, 4 belonged to 2 families. Of the other 4, 2 were first children and the other 2 had negative family histories. Congenital hepatic fibrosis is undoubtedly a variant of the commoner congenital cystic liver (Parker, 1956). The two conditions may reflect variations in the extent and severity of the same disease, the more severely affected patients with marked fibrosis, presenting early in life, while the milder cases present later 
without much fibrosis or portal hypertension but with cysts visible to the naked eye. Kerr et al. (1961) concluded that the severe childhood variant was nevertheless a distinct entity. There are several points in favour of this view. (i) Though both conditions are familial, there has been no reported instance of the two variants occurring in the same family. (ii) Judging from the number of reported cases, the incidence of the more benign adult disease is higher generally than the form described here in children. In spite of this, we have encountered 8 cases of the childhood type as compared with only 2 of the adult type in the past 8 years. (iii) Family studies of congenital cystic liver suggest that it is inherited as a Mendelian dominant, with high penetrance and variable expressivity, while a study of the relatively fewer familial cases of congenital fibrosis suggests a recessive mode of inheritance. (iv) Several children with congenital hepatic fibrosis diagnosed in infancy, have been operated on in the second decade without visible cysts being detected (Kerr et al., 1961).

The mode of presentation and clinical course followed by our patients differs slightly from the clinical picture described by Kerr et al. (1961). They stressed portal hypertension, with bleeding from oesophageal varices as being a prominent feature. Although splenomegaly has been a feature of all but one of our cases, we are not aware of the occurrence of haematemesis or melaena in any of them. Oesophageal varices were demonstrated in only one of the cases coming to necropsy, and barium studies performed in 2 of the 3 living patients, aged $5 \frac{1}{2}$ and 10 years, failed to demonstrate varices. No necropsy was performed on Case 4, so they cannot be excluded in her case. In Kerr et al.'s series, and in their review of 24 patients recognized retrospectively, gastro-intestinal bleeding did not occur before the age of 3 years and rarely before 5 years. This fact may account for the absence of this symptom in our patients, as 5 of them were under 3 years at the time of study.

In our patients, the most prominent clinical features were anaemia and recurrent infections. Whether the former is a consequence of the latter, and the latter a consequence of the liver disease, we have been unable to determine.

Examination of the chromosomes in 3 children showed no abnormalities. P. E. Conen (personal communication) has also investigated 3 cases of congenital fibrosis with negative results.

Histologically our cases seem to differ from those described by others (Parker, 1956; Kerr et al., 1961; Hickie and Garvan, 1962), mainly in that there was more evidence of an inflammatory cellular exudate and that-possibly related-there was absence of a sharp delineation from the surrounding parenchyma. There appears, however, no reason to question that they all belong to the same disease entity. As in fibrosis from other causes, inflammation and further invasion of the parenchyma may occur relatively unrelated to the original disease. The cellular infiltrate was on the whole not much in evidence in the biopsies, but was more pronounced at necropsy.

We have no opinion regarding the deficiency of the terminal branches of the portal vein, as discussed by Kerr et al. (1961); in the absence of injection studies and serial reconstruction, we could not contribute towards this aspect.

In all cases with polycystic disease of the kidneys, the latter were greatly enlarged and showed cystic dilatation of the tubules, especially in the medulla. Osathanondh and Potter (1964) state categorically that type 1 polycystic kidneys cause death soon after birth. In spite of this, we feel that Cases 1 and 2 are of this variety. Case 6 appeared to be type 3 . We are not in a position to say whether or not there is a basic difference between types 1 and 3 that could not be explained by increasing age of the patient, with complications due to infection and hypertension. This, we feel, merits further study, because it would be remarkable to have an identical disease of the liver with a strong familial tendency associated with two different diseases of the kidney.

The other remarkable feature, present in all the necropsies, was the severe degree of lymphadenopathy in the abdominal lymph nodes. Histologically, these lymph nodes showed only lymphoid hyperplasia and, in some, extramedullary haemopoiesis. It is well recognized in this department that children under the age of 3 , dying from almost any cause, have mesenteric lymphadenopathy at necropsy. The nodes usually measure up to 1.0 to $1.5 \mathrm{~cm}$. in diameter. In the cases described here, however, the lymph nodes were much larger, up to $2.5 \mathrm{~cm}$. in diameter, and other groups besides the mesenteric nodes were affected.

The exact nature of the lesion involved in producing congenital hepatic fibrosis and polycystic kidneys remains obscure, apart from the obviously hereditary aspect. Norris and Tyson (1947) concluded from their reconstruction studies that it was due to segmentation of the bile-ducts at an early stage in intrauterine life, with resulting increase in numbers and dilatation of isolated ducts. A similar factor would presumably operate in the kidneys. Dissection of the nephrons in one of our cases does not suggest the separation of cystic areas. These were directly continuous with the lumen of the tubules. One can conjecture on an inborn error 
of metabolism resulting in excretion of an abnormal metabolite, which, being concentrated in the bileducts and renal tubules might cause local damage resulting in dilatation, and cystic change, complicated later by infection and fibrosis. This might account for the differences between the adult and the childhood variants.

\section{Summary}

Clinical and pathological data are presented on 8 children with the syndrome described as congenital hepatic fibrosis. The karyotypes were normal in the 3 children in whom this examination was undertaken. 4 also had polycystic disease of the kidneys. These studies emphasize the presence of recurrent fevers and infections and severe anaemia as being important features when the disease occurs in early childhood. Clinical portal hypertension was not seen. As in previous studies, a strong familial tendency was encountered. The exact aetiology remains obscure.

We would like to thank Professor E. H. Back and Professor $\mathrm{H}$. Annamunthodo for permission to use their cases. The cytogenetic studies were supported by a grant from the Wellcome Trust and the Standing Advisory Committee for Medical Research in the Caribbean.

\section{REFERENCES}

Althoff, H. (1964). UUber familiäres Vorkommen intrahepatischer Gallengangswucherungen (cholangiodysplastische Pseudoleberzirrhose). Zbl. allg. Path. path. Anat., 324, 105.

Arakaki, D. T., and Sparkes, R. S. (1963). Microtechnique for culturing leukocytes from whole blood. Cytogenetics, 2, 57.

Comfort, M. W., Gray, H. K., Dahlin, D. C., and Whitesell, F. B., Jr. (1952). Polycystic disease of the liver: a study of 24 cases. Gastroenterology, 20, 60.

Dalgaard, O. Z. (1957). Bilateral polycystic disease of the kidneys: a follow-up of 284 patients and their families. Acta med. scand., Suppl. 328.

Elias, H. (1953). Morphology of the liver. In Liver Injury. Transactions of the Eleventh Conference, 1952, p. 111. J. Macy, Jr. Foundation, New York.

Hickie, J. B., and Garvan, J. M. (1962). Congenital hepatic fibrosis. Aust. Ann. Med., 11, 260.

Kerr, D. N. S., Harrison, C. V., Sherlock, S., and Walker, R. Milnes (1961). Congenital hepatic fibrosis. Quart. F. Med., 30, 91.

MacMahon, H. E. (1929). Congenital anomalies of the liver. Amer. F. Path., 5, 499.

- (1955). Biliary cirrhosis. Differential features of the five types. Lab. Invest., 4, 243.

Melnick, P. J. (1955). Polycystic liver: analysis of seventy cases. Arch. Path., 59, 162.

Moschcowitz, E. (1906). Non-parasitic cysts (congenital) of the liver, with a study of aberrant bile ducts. Amer. F. med. Sci., $131,674$.

Norris, R. F., and Tyson, R. M. (1947). The pathogenesis of polycystic livers. Reconstructions of cystic elements in 2 cases. Amer. F. Path., 23, 201.

Osathanondh, V., and Potter, E. L. (1964). Pathogenesis of polycystic kidneys. Arch. Path., 77, 459.

Parker, R. G. F. (1956). Fibrosis of the liver as a congenital anomaly. F. Path. Bact., 71, 359.

Sweetnam, W. P., and Sykes, C. G. W. (1961). Congenital fibrosis of the liver as a familial defect. Lancet, 1, 374.

Williams, R., Scheuer, P. J., and Heard, B. E. (1964). Congenital hepatic fibrosis with an unusual pulmonary lesion. $\mathcal{F}$. clin. Path., 17, 135. 